\title{
Occurrence of 2 Primary Rare Tumors on the Scalp of a 43-Year-Old Woman
}

\author{
Clarissa Mitri Espanhol Manoella Freitas Santos Claurio Roncuni Ferreira \\ Roque Domingos Furian Virgílio Zanella Leandro Damiani
}

Dermatology Department, Hospital Santa Casa de Misericórdia de Porto Alegre, Porto Alegre, Brazil; Head and Neck Surgery Department, Hospital Santa Casa de Misericórdia de Porto Alegre, Porto Alegre, Brazil

\section{Question}

A woman in her early forties (43-year-old) presented to the Head and Neck Surgery Department of the Hospital Santa Casa in Porto Alegre, in 2010, with a normochromic papule on the scalp that she had noticed 6 months earlier. An incisional biopsy was performed. Excision for margin expansion was chosen as treatment. The histopathologic exam demonstrated margins free of the lesion. After 5 years, the patient returned with a nodule in the cervical region. An excisional cervical lymph node biopsy was performed, with positive immunohistochemistry for carcinoembryonic antigen (CEA)-M, epithelial membrane antigen (EMA), and cytokeratin AE1 + AE2 (CKM), which confirmed metastasis of the primary tumor. The patient underwent cervical lymph node dissection and radiotherapy on the right side of the cervical region. In 2018 , the patient returned with a new retroauricular lesion on the right side, which was an erythematous plaque with central erosion; at dermoscopy, there were clods and atypical and arborizing vessels (Fig. 1,2). The histopathology of a new biopsy revealed tubulocystic structures lined by basaloid cells with syringoma-like tadpole morphology (Fig. 3, 4). The patient underwent a new surgery for margin expansion and then was referred for dermatological evaluation. Currently, she is on follow-up at the Dermatology Department of the Hospital Santa Casa in Porto Alegre.

What is your diagnosis?

\section{KARGER}

(C) 2019 S. Karger AG, Basel

E-Mail karger@karger.com

www.karger.com/sad
Clarissa Mitri Espanhol

Dermatology Department, Santa Casa de Misericórdia de Porto Alegre Independência Avenue 190/304

Porto Alegre 90035070 (Brazil)

E-Mail mitriclarissa@gmail.com 


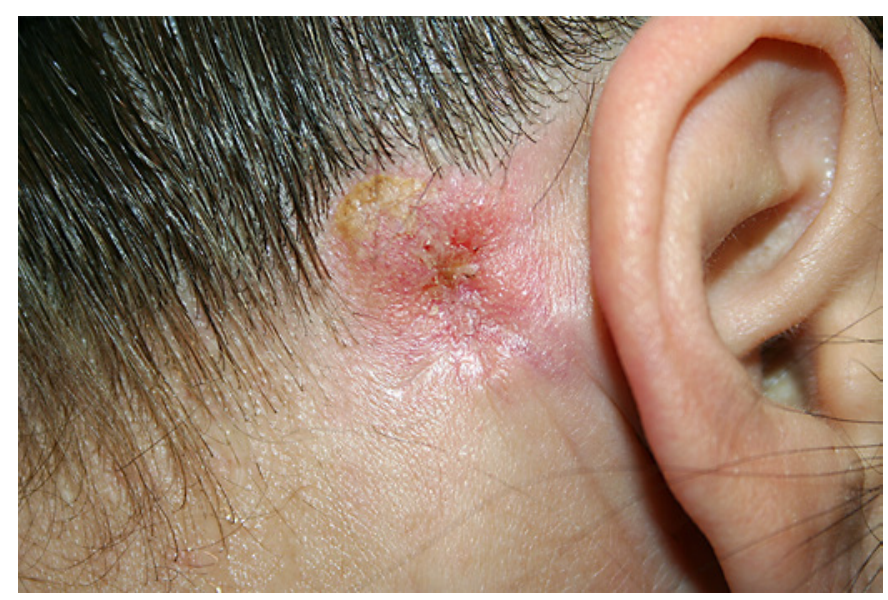

Fig. 1. Retroauricular lesion: erythematous plaque with central erosion.

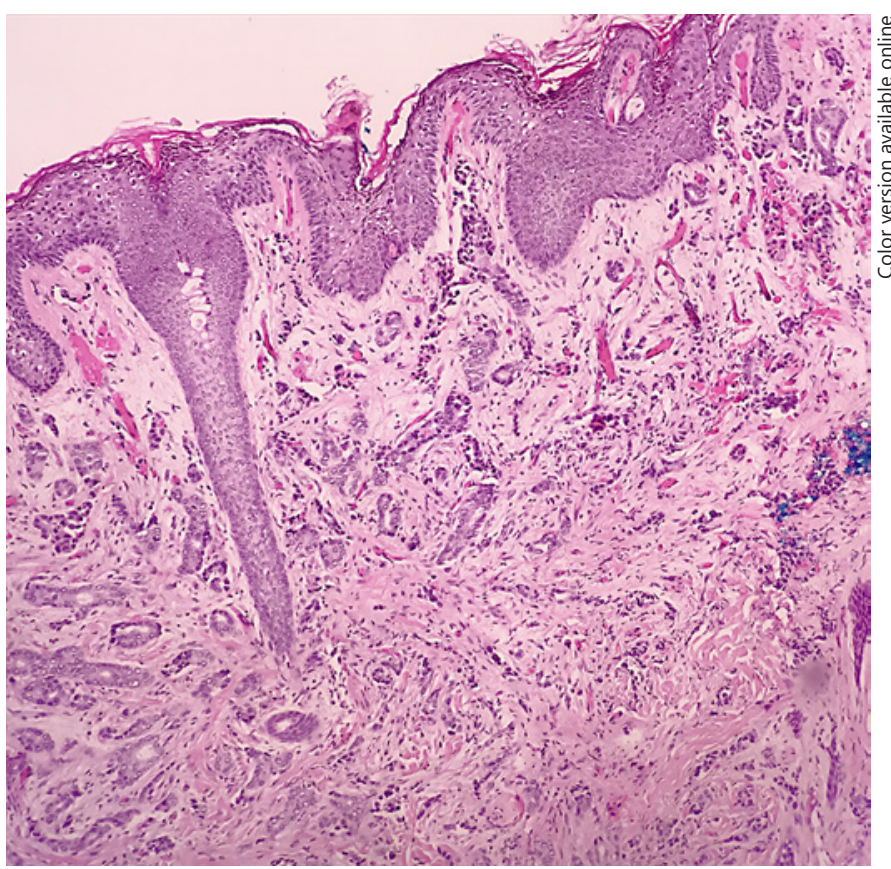

Fig. 3. Syringoid eccrine carcinoma extending to the reticular dermis $(\mathrm{HE}, \times 10)$.

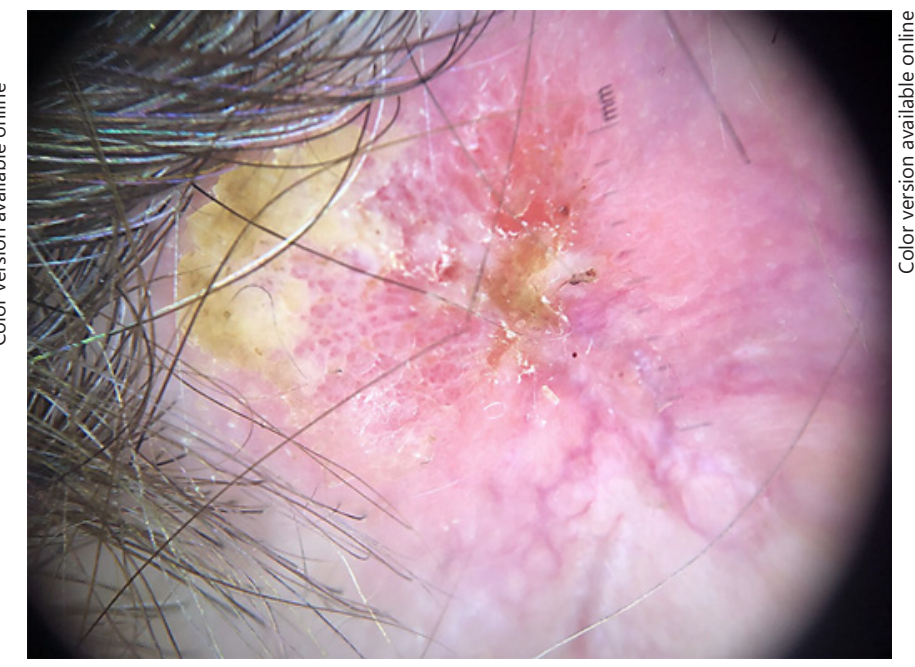

Fig. 2. Dermoscopy: erythematous plaque with central erosion, clods, and atypical and arborizing vessels.

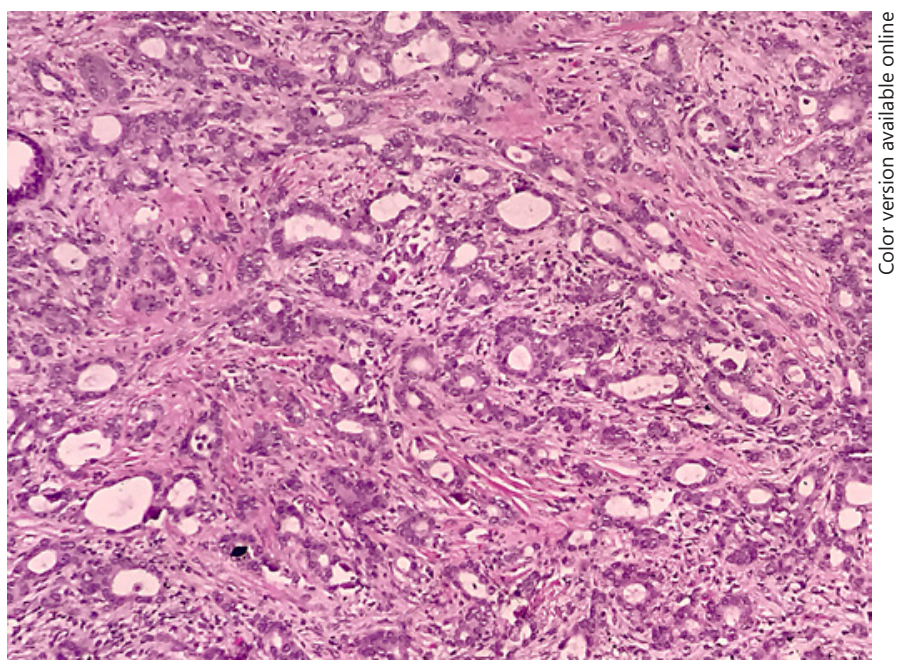

Fig. 4. The tumor is composed of tubulocystic structures lined by basaloid cells with syringoma-like tadpole morphology (HE, $\times 40$ ). 


\section{Answer}

The histopathology of the case was compatible with syringoid eccrine carcinoma (SEC). SEC is a rare tumor, accounting for less than $0.01 \%$ of all skin cancers $[1,2]$. The classification is very complex since several different terms are used to describe the same tumor. As a broad histologic spectrum is often seen, the exact origin of these lesions is unknown [3-6].

It is believed that the origin is from the eccrine glands. First described as a basal cell tumor with eccrine differentiation, in 1969, it already had several terminologies, including malignant syringoma and the original term eccrine epithelioma (basal cell tumor with eccrine differentiation) [7-11]. It usually manifests in the fifth and sixth decades of life as a nodule or slow-growing plaque on the head and neck region and, less commonly, on the trunk. The clinical presentation can be nonspecific, and the tumor usually has an indolent course [12]. The involvement of the extremities is uncommon. These tumors are highly invasive, can be locally aggressive, and often metastasize (more than 60\%). Histologically, SEC exhibit syringomalike tadpole morphology composed of basaloid cells with ductal differentiation within a fibrocollagenous matrix. Deep invasion is commonly seen. Immunohistochemically, SEC can show expression of cytokeratins, EMA, and CEA [13]. The choice of treatment is usually surgical, with margin enlargement in localized lesions. Chemotherapy and radiotherapy are performed when there is local metastasis [7-13].

In the case reported, the tumor developed in a young 43 -year-old female, first on the scalp, followed by cervical and lymph node metastases, and the treatment was excision of the entire lesion, with margins, cervical emptying, and radiotherapy. The second lesion located on the retroauricular region was confirmed as a primary lesion of SEC, which is very rare. In conclusion, SEC diagnosis can be a challenge and should be considered as a differential diagnosis in lesions with no specific pattern and dermoscopy, especially when occurring in head and neck areas. A multidisciplinary approach is important. We report the case of a young patient with 2 primary lesions of SEC to increase the awareness of this rare tumor.

\section{Statement of Ethics}

The patient was informed and gave her consent to describe the case.

\section{Disclosure Statement}

The authors declare no conflicts of interest.

\section{Keywords}

Clinicopathologic correlation - Scalp disease - Surgery ·

Tumor

\section{References}

1 Tulenko JF, Conway H. An analysis of sweat gland tumors. Surg Gynecol Obstet. 1965 Aug; 121:343-8.

2 Moy RL, Rivkin JE, Lee H, Brooks WS, Zitelli JA. Syringoid eccrine carcinoma. J Am Acad Dermatol. 1991 May;24(5 Pt 2):857-60.

3 Alsaad KO, Obaidat NA, Ghazarian D. Skin adnexal neoplasms-part 1: an approach to tumours of the pilosebaceous unit. J Clin Pathol. 2007 Feb;60(2):129-44.

4 Obaidat NA, Alsaad KO, Ghazarian D. Skin adnexal neoplasms-part 2: an approach to tumours of cutaneous sweat glands. J Clin Pathol. 2007 Feb;60(2):145-59.

5 Urso C, Bondi R, Paglierani M, Salvadori A, Anichini C, Giannini A. Carcinomas of sweat glands: report of 60 cases. Arch Pathol Lab Med. 2001 Apr;125(4):498-505.
6 Urso C, Paglierani M, Bondi R. Histologic spectrum of carcinomas with eccrine ductal differentiation (sweat-gland ductal carcinomas). Am J Dermatopathol. 1993 Oct;15(5): 435-40.

7 Freeman RG, Winkelmann RK. Basal cell tumor with eccrine differentiation (eccrine epithelioma). Arch Dermatol. 1969 Aug;100(2): 234-42.

8 Glatt HJ, Proia AD, Tsoy EA, Fetter BF, Klintworth GK, Neuhaus R, et al. Malignant syringoma of the eyelid. Ophthalmology. 1984 Aug;91(8):987-90.

9 Lipper S, Peiper SC. Sweat gland carcinoma with syringomatous features: a light microscopic and ultrastructural study. Cancer. 1979 Jul;44(1):157-63.
10 Cooper PH, Mills SE, Leonard DD, Santa Cruz DJ, Headington JT, Barr RJ, et al. Sclerosing sweat duct (syringomatous) carcinoma. Am J Surg Pathol. 1985 Jun;9(6):422-33.

11 Sánchez NP, Winkelmann RK. Basal cell tumor with eccrine differentiation (eccrine epithelioma). J Am Acad Dermatol. 1982 Apr; 6(4 Pt 1):514-8.

12 Cho WC, Wagner B, Gulosh M, Elaba Z. Syringoid Eccrine Carcinoma of the Foot: Report of a Rare Cutaneous Adnexal Neoplasm. Int J Surg Pathol. 2017 Oct;25(7):659-64.

13 Sidiropoulos M, Sade S, Al-Habeeb A, Ghazarian D. Syringoid eccrine carcinoma: a clinicopathological and immunohistochemical study of four cases. J Clin Pathol. 2011 Sep; 64(9):788-92. 